\title{
Escherichia coli type III secretion system 2 (ETT2) is widely distributed in avian pathogenic Escherichia coli isolates from Eastern China
}

\author{
S. WANG ${ }^{1}, X . \mathrm{LIU}^{1,2}, \mathrm{X} . \mathrm{XU}^{1}, \mathrm{Y} \cdot \mathrm{ZHAO}^{1}, \mathrm{D} \cdot \mathrm{YANG}^{1}, \mathrm{X} \cdot \mathrm{HAN}^{1}, \mathrm{M} \cdot \mathrm{TIAN}^{1}$, \\ C. DING ${ }^{1}$, D. PENG ${ }^{2}$ AND S. YU ${ }^{1 *}$ \\ ${ }^{1}$ Shanghai Veterinary Research Institute, Chinese Academy of Agricultural Sciences, Shanghai, China \\ ${ }^{2}$ College of Veterinary Medicine, Yangzhou University, Yangzhou, China
}

Received 17 December 2015; Final revision 5 April 2016; Accepted 5 April 2016;

first published online 22 April 2016

\section{SUMMARY}

Pathogens utilize type III secretion systems to deliver effector proteins, which facilitate bacterial infections. The Escherichia coli type III secretion system 2 (ETT2) which plays a crucial role in bacterial virulence, is present in the majority of E. coli strains, although ETT2 has undergone widespread mutational attrition. We investigated the distribution and characteristics of ETT2 in avian pathogenic E. coli (APEC) isolates and identified five different ETT2 isoforms, including intact ETT2, in 57.6\% (141/245) of the isolates. The ETT2 locus was present in the predominant APEC serotypes O78, O2 and O1. All of the ETT2 loci in the serotype O78 isolates were degenerate, whereas an intact ETT2 locus was mostly present in $\mathrm{O} 1$ and $\mathrm{O} 2$ serotype strains, which belong to phylogenetic groups $\mathrm{B} 2$ and $\mathrm{D}$, respectively. Interestingly, a putative second type III secretion-associated locus (eip locus) was present only in the isolates with an intact ETT2. Moreover, ETT2 was more widely distributed in APEC isolates and exhibited more isoforms compared to ETT2 in human extraintestinal pathogenic E. coli, suggesting that APEC might be a potential risk to human health. However, there was no distinct correlation between ETT2 and other virulence factors in APEC.

Key words: Avian pathogenic Escherichia coli, distribution, Escherichia coli type III secretion system 2.

\section{INTRODUCTION}

Many pathogens utilize type III secretion systems (T3SSs) to deliver effectors into eukaryotic cells, which facilitates infections [1, 2]. Most bacteria contain only one T3SS, but some pathogens harbour multiple T3SSs, which function independently in different aspects of pathogenesis. Salmonella utilize the Salmonella pathogenicity island 1 (SPI-1) T3SS to invade host cells, while the SPI-2 T3SS is required for intracellular survival [3]. Intestinal pathogenic Escherichia coli, such as enteropathogenic E. coli

\footnotetext{
* Author for correspondence: Professor S. Yu, Shanghai Veterinary Research Institute, Chinese Academy of Agricultural Sciences, Shanghai 200241, China.

(Email: yus@shvri.ac.cn)
}

(EPEC) and enterohaemorrhagic E. coli (EHEC), use the locus of enterocyte effacement (LEE)-encoded T3SS to cause attaching/effacing lesions and diarrhoeal disease [4]. A second T3SS, designated the E. coli type III secretion system 2 (ETT2), was identified by sequencing the genome of an EHEC O157 strain [5]; however, the role of ETT2 in E. coli infections is less clear.

ETT2 is unable to encode a functional secretion system in most $E$. coli because it has undergone widespread mutational attrition, but it plays a role in regulating bacterial virulence $[6,7]$. ETT2 can affect the expression of virulence genes outside the ETT2 cluster, and it is indirectly involved in the virulence of intestinal pathogenic E. coli [EHEC and enteroaggregative E. coli (EAEC)] [8, 9]. However, ETT2 is 
crucial for the virulence of extraintestinal pathogenic E. coli (ExPEC) strains. The ETT2 locus in avian pathogenic E. coli (APEC), although degenerate, contributes to virulence and reduced serum survival [10]. Moreover, some evidence suggests that intact ETT2 might deliver effector proteins into human brain microvascular endothelial cells (HBMECs) to enhance bacterial invasion, intracellular survival and virulence of newborn meningitis $E$. coli (NMEC) strains [11].

ETT2 is known to be present, in whole or in part, in the majority of $E$. coli strains; it is most frequent in intestinal pathogenic E. coli strains [12-14], but of low prevalence in uropathogenic E. coli (UPEC) strains [15]. ExPEC strains (NMEC, UPEC, APEC) share a broad range of similar virulence factors and pathogenic mechanisms and APEC is thought to be a potential reservoir for human ExPEC [16-18]. Thus, this study investigated the prevalence and characteristics of ETT2 in APEC isolates to elucidate the potential zoonotic risk of APEC.

\section{MATERIALS AND METHODS}

\section{Bacterial strains, growth conditions and DNA preparation}

A strain collection containing 245 APEC isolates obtained from chickens, ducks or geese with typical colibacillosis symptoms in Eastern China was screened for the ETT2 locus (Supplementary Table S1). The ETT2-positive EHEC O157 strain ATCC43999 and the ETT2-negative strain DE719 [19] were used as controls in polymerase chain reaction (PCR) amplifications. All E. coli isolates were routinely grown in Luria-Bertani broth at $37^{\circ} \mathrm{C}$ with aeration. Bacterial genomic DNA was prepared using the TIANamp Bacterial DNA kit (Tiangen, China) according to the manufacturer's guidelines.

\section{Serotyping}

The serotype of each APEC isolate was identified by an allele-specific PCR assay as described previously [20] and confirmed by agglutination with specific hyperimmune rabbit antisera to $\mathrm{O} 1, \mathrm{O} 2$ and $\mathrm{O} 78$ (Statens Serum Institut, Denmark) according to the manufacturer's guidelines.

\section{Phylogenetic grouping}

All isolates were classified into phylogenetic groups (A, B1, B2, D) according to the presence of the
chuA and yja $A$ genes, and an anonymous DNA fragment, TSPE4.C2 by a triplex PCR as described previously [21].

\section{Detection of ETT2}

Isolates were tested for the presence of ETT2 genes by eight tiling-path PCR (TP-PCR), consisting of several interlocking, PCR-based approaches [6]. A series of primers was designed to amplify long fragments that spanned the entire ETT2 region in EHEC O157:H7 (GenBank accession no. NC002695.1) (Table 1). The structure of ETT2 cluster of EHEC O157:H7, EAEC 042 and NMEC CE10 are displayed in Figure $1 a$. If the long-fragment PCR was negative, a relevant short overlap PCR with the same primers and/or a deletion-scanning, long-fragment PCR employing primers flanking the lost segments was performed (Fig. 1b). The distribution of the eip locus, which encodes homologues of SPI-1 translocators and additional T3SS-related proteins, was determined by PCR with the respective primers (Table 1).

Long-fragment PCRs were performed using LA Taq DNA polymerase (TaKaRa, China). For shortfragment PCRs, $1 \mu 1$ template DNA was added to reaction mixtures $(25 \mu \mathrm{l})$ containing $2.5 \mu \mathrm{l}$ of $10 \times$ PCR buffer with $\mathrm{MgCl}_{2}$ (25 mM), 1.5 U Taq DNA polymerase (TaKaRa), $2 \mu \mathrm{l}$ dNTPs $(2.5 \mathrm{~mm}$ for each dNTP), and $0.5 \mu \mathrm{l}(10 \mu \mathrm{M})$ of each primer pair. The PCR mixtures were subjected to the following conditions in an ABI Thermal Cycler (ABI Biosystems, USA): pre-denaturation at $95^{\circ} \mathrm{C}$ for $5 \mathrm{~min}$, followed by 30 cycles of $95^{\circ} \mathrm{C}$ for $35 \mathrm{~s}, 50^{\circ} \mathrm{C}$ for $30 \mathrm{~s}$ and $72{ }^{\circ} \mathrm{C}$ for different times, followed by a final extension at $72{ }^{\circ} \mathrm{C}$ for $10 \mathrm{~min}$. Following electrophoresis, PCR products were identified by UV illumination, sequenced, and submitted to GenBank.

\section{Virulence genes}

Isolates were screened by a previously described multiplex PCR protocol for the virulence genes fim $C$, papC, tsh, mat, irp2, fyuA, iroN, iucD, iss, cvalcvi, neuC, ompA, vat, ibe $A$ and ibe $B$ [22].

\section{RESULTS}

\section{Identification and characterization of the ETT2 locus}

In total, 57.6\% (141/245) APEC isolates were positive for ETT2 gene sequences (Table 2). TP-PCR amplification and sequencing identified five different ETT2 
Table 1. Primers used in the present study

\begin{tabular}{|c|c|c|c|}
\hline Primers & Sequences $\left(5^{\prime}-3^{\prime}\right)$ & Target genes & PCR product size \\
\hline EC ETT2a-F & ACGCTGATCGTGGGTATCCT & yqeG & $3118 \mathrm{bp}$ \\
\hline EC ETT2a-R & CTCACGATCTGTCAATGATGAG & yqeK & \\
\hline EC ETT2b-F & GAGTCGAACTCGACATTCATC & yqeK & $3584 \mathrm{bp}$ \\
\hline EC ETT2b-R & CTGGGTTCGAGTTGTAGTGA & ygeH & \\
\hline EC ETT2c-F & CTGATAACTGGTCTGTCTGGAC & ygeH & $3907 \mathrm{bp}$ \\
\hline EC ETT2c-R & TGCAGATGCACTCGTTTCATC & eprK & \\
\hline EC ETT2d-F & ACTATCGCCAGTATCAACATCG & eprK & $3894 \mathrm{bp}$ \\
\hline EC ETT2d-R & СTCATACTGTATTGTCTCGGCAG & epaS & \\
\hline EC ETT2e-F & TGTGAGTAGGGTTGGCAATC & epas & $3310 \mathrm{bp}$ \\
\hline EC ETT2e-R & GATAGCAGAAGAGAGTGGCAG & ераO & \\
\hline EC ETT2f-F & GAGCTGGACTCAATACTCCATC & ераO & $2872 \mathrm{bp}$ \\
\hline EC ETT2f-R & GCAGAACTTGACGACGTTTCTG & eivC & \\
\hline EC ETT2 g-F & СCTGGCTATACGTTCATTTGC & eiv $C$ & $6321 \mathrm{bp}$ \\
\hline EC ETT2 g-R & AGGTCTGGTTGTGACATCGAC & ECs 3735 & \\
\hline EC ETT2 h-F & GTCGGATTTACGAATCATGAGA & ECs 3735 & $2553 \mathrm{bp}$ \\
\hline EC ETT2 h-R & GGGATTGATATCTCAGCTCCAC & ECs 3738 & \\
\hline $\mathrm{EC}$ eicA-F & CAGAGCTGCATGGCATTACT & eicA & $369 \mathrm{bp}$ \\
\hline EC eicA-R & CAAGATAAGCAGTAGCCATCTC & eic $A$ & \\
\hline EC eipB-F & ACAGCCATTATGGATGCTGA & eip $B$ & $610 \mathrm{bp}$ \\
\hline EC eipB-R & TCGTATCTTGATCGACACCA & eip $B$ & \\
\hline EC eipX-F & CAAGCAGTTCTACAGAGCAGAC & eip $X$ & $738 \mathrm{bp}$ \\
\hline EC eipX-R & GATCCAGATAGCTACTCATAACTG & eip $X$ & \\
\hline EC eipD-F & GAGTTCTGCACCTGAAGTGAG & eipD & $557 \mathrm{bp}$ \\
\hline EC eipD-R & CTGAAGACTGACTCATACTGTC & eipD & \\
\hline EC eilA-F & GTACCTATTGTGATTGTGACCG & eilA & $465 \mathrm{bp}$ \\
\hline EC eilA-R & CATAACAGCAGAATCCAGAGA & eilA & \\
\hline EC eaeX-F & CGTTACTGTGACGGTTAATGG & eaeX & $478 \mathrm{bp}$ \\
\hline EC eaeX-R & GACGATTGCCAGTACCAATCAG & eaeX & \\
\hline
\end{tabular}

isoforms among the isolates (GenBank accession nos. KU684467-KU684471). Sequence analysis indicated that the intact ETT2 gene cluster in APEC was similar to that of NMEC CE10, which was designated the type A isoform. Types B, D and E isoforms were characterized by $4.99-, 5 \cdot 68-$ and $8 \cdot 74-\mathrm{kb}$ gene deletions, respectively, in the right end of the ETT2 island. Specifically, there was a $1 \cdot 3-\mathrm{kb}$ transposase insertion in the transcriptional regulation gene ygeH, and a 4.99-kb gene deletion in the ETT2 island of the type $\mathrm{C}$ isoform strains (Fig. 1c). Of the five different ETT2 isoforms detected, type E $(51 \cdot 1 \%, 72 / 141)$ was the most widely distributed, followed by type $\mathrm{C}$ $(14 \cdot 9 \%, 21 / 141)$ and type B $(12 \cdot 8 \%, 18 / 141)$.

\section{ETT2 locus in predominant APEC serotypes}

As shown in Table 2, 46.9\% (115/245) of the isolates were grouped as serotype $\mathrm{O} 78,22 \cdot 5 \%(55 / 245)$ as serotype $\mathrm{O} 2$, and $12.7 \%(31 / 245)$ as serotype $\mathrm{O} 1$; the remaining 44 isolates $(18 \%)$, were not typable with these three antisera and were classified as 'Non-O1/
O2/O78' serotypes. The majority $(64 \cdot 4 \%, 74 / 115)$ of the $\mathrm{O} 78$ serotype isolates were positive for ETT2, as were $58.2 \%(32 / 55)$ of serotype $\mathrm{O} 2$, and $48.4 \%$ $(15 / 31)$ of serotype O1. Correspondingly, of the 141 APEC isolates positive for ETT2, 52.5\% (74) were serotype $\mathrm{O} 78,22 \cdot 7 \%$ (32) serotype $\mathrm{O} 2$, and $10 \cdot 6 \%$ (15) serotype $\mathrm{O} 1$. The remaining $20(14 \cdot 2 \%)$ isolates belonged to 'Non-O1/O2/O78' serotypes. An intact ETT2 island (type A) was found only in serotypes $\mathrm{O} 1$ and $\mathrm{O} 2$ and notably the $\mathrm{O} 78$ isolates always contained deleted isoforms of ETT2.

\section{Phylogenetic groups D and B2 APEC, and ETT2 cluster}

According to the Clermont E. coli phylotyping method [21], $78(31.8 \%)$ of the APEC isolates belonged to phylogenetic group B2, while $54(22 \%)$, $52(21 \cdot 2 \%)$ and $48(19 \cdot 6 \%)$ of the isolates fell in groups $\mathrm{D}, \mathrm{A}$ and $\mathrm{B} 1$, respectively; $13(5 \cdot 8 \%)$ of the isolates could not be classified into a phylogenetic group (Table 2). A comparison of the distribution of the 
(a)
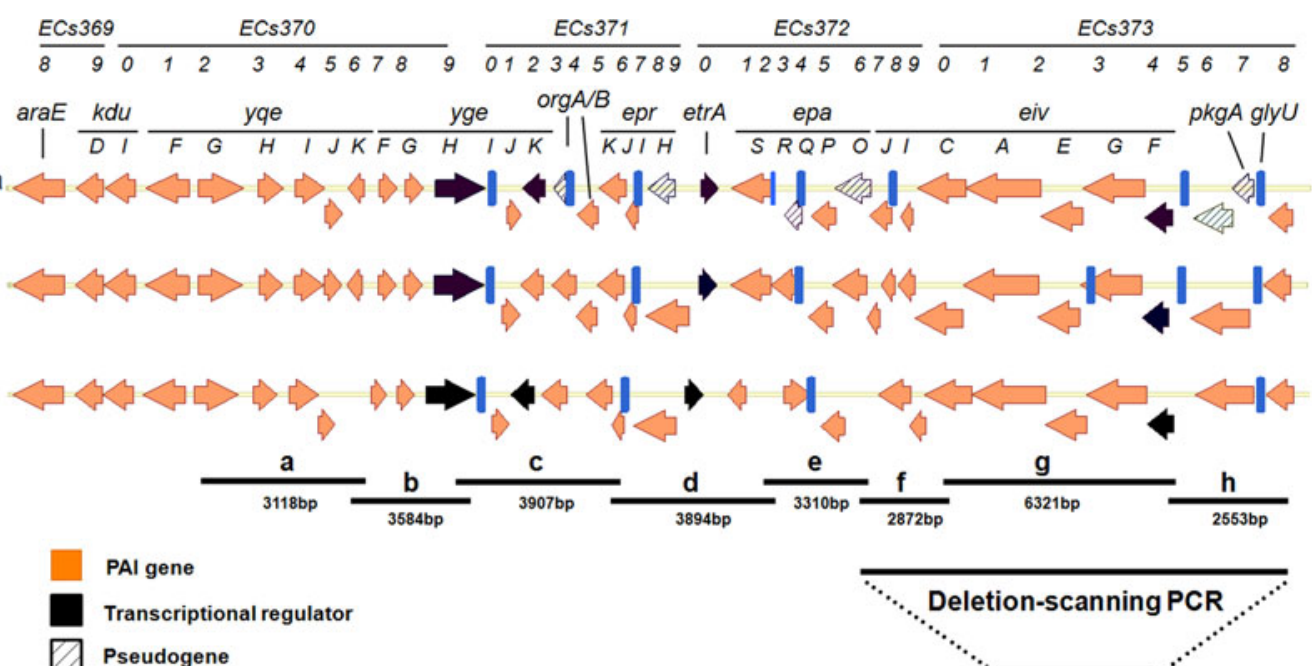

Dseudogene

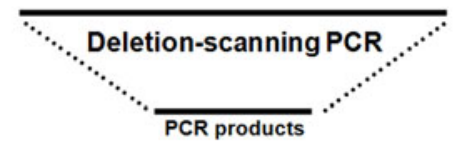

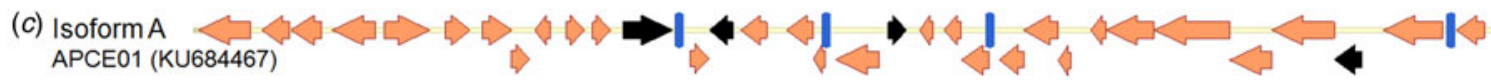

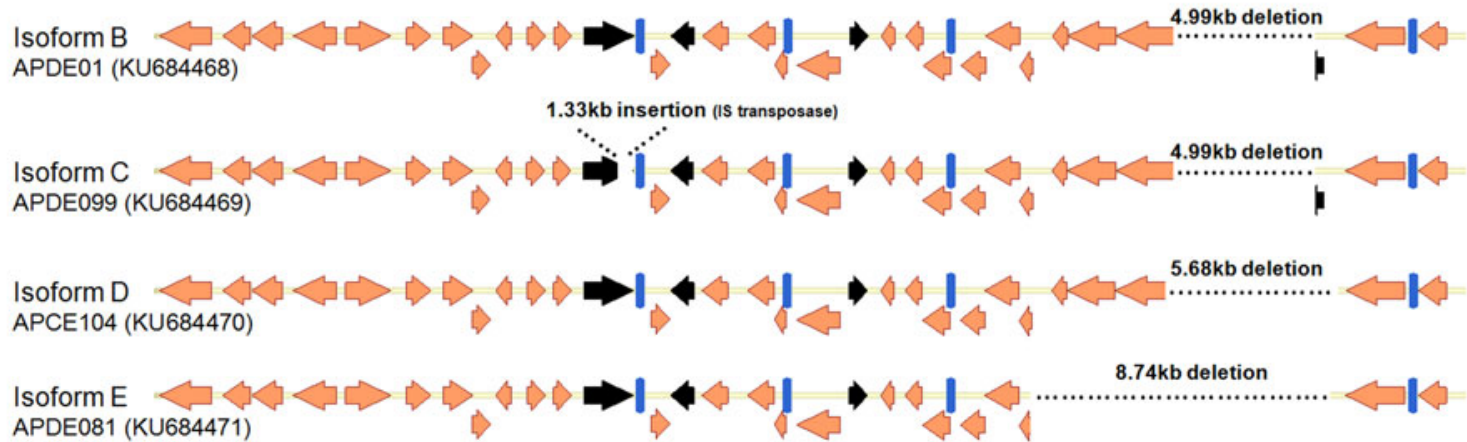

Fig. 1. ETT2 structures and lengths of TP-PCR products. (a) Structure of the ETT2 pathogenicity island in EHEC O157: H7, EAEC 042 and NMEC CE10. Homologous genes are vertically aligned with the transcriptional regulator encoding gene shown as black and the pseudogene as a grid. (b) Bold lines indicate the size of the PCR products, and deletion-scanning PCR. (c) Length of gene deletion or insertion of ETT2 isoforms in APEC isolates.

Table 2. Distribution of the ETT2 isoforms in APEC isolates

\begin{tabular}{|c|c|c|c|c|c|c|c|}
\hline & \multicolumn{5}{|c|}{ ETT2 positive $(n=141)$, isoforms } & \multirow{2}{*}{$\begin{array}{l}\text { ETT2 negative } \\
(n=104)\end{array}$} & \multirow[b]{2}{*}{ Total $(n=245)$} \\
\hline & $\mathrm{A}(n=17)$ & $\mathrm{B}(n=18)$ & $\mathrm{C}(n=21)$ & $\mathrm{D}(n=13)$ & $\mathrm{E}(n=72)$ & & \\
\hline \multicolumn{8}{|l|}{ Serotypes } \\
\hline $\mathrm{O} 1$ & 9 & 2 & 1 & 1 & 2 & 16 & 31 \\
\hline $\mathrm{O} 2$ & 5 & 4 & 2 & 9 & 12 & 23 & 55 \\
\hline $\mathrm{O} 78$ & 0 & 10 & 16 & 2 & 46 & 41 & 115 \\
\hline Non-O1/O2/O78 & 3 & 2 & 2 & 1 & 12 & 24 & 44 \\
\hline \multicolumn{8}{|l|}{ Phylogenetic groups } \\
\hline A & 1 & 8 & 11 & 0 & 11 & 21 & 52 \\
\hline B1 & 1 & 0 & 4 & 2 & 25 & 16 & 48 \\
\hline B2 & 5 & 5 & 2 & 7 & 16 & 43 & 78 \\
\hline $\mathrm{D}$ & 9 & 3 & 1 & 4 & 18 & 19 & 54 \\
\hline Unknown & 1 & 2 & 3 & 0 & 2 & 5 & 13 \\
\hline
\end{tabular}


ETT2 cluster among phylogenetic groups revealed that $66 \cdot 7 \%(32 / 48), 64 \cdot 8 \%(35 / 54), 59 \cdot 6 \%(31 / 52)$ and $44.9 \%(35 / 78)$ of the group B1, D, A and B2 isolates, respectively, and $61 \cdot 5 \%(8 / 13)$ of the unknown group were positive for the ETT2 island. For the 17 isolates that had an intact ETT2 (type A isoform), nine fell in phylogenetic group D, five in B2, whereas types B and $\mathrm{C}$ isoforms were predominant in phylogenetic group $\mathrm{A}$ isolates, and type E in group B1.

\section{Type III secretion-associated locus (eip locus), virulence genes and ETT2 locus}

According to previous studies, the eip locus within the EAEC 042 genome is associated with the $\operatorname{sip} A B C D$ homologue cluster of the ETT2 locus [6, 23]. Here, the eip locus was only found in APEC strains that possess an intact ETT2 locus and, moreover, was located between the E. coli yicM and $\operatorname{llp} A$ genes (data not shown), which is in the same position as that in EAEC 042 and NMEC CE10.

There was no correlation between the presence or distribution of other virulence genes and the ETT2 locus (Supplementary Table S1).

\section{DISCUSSION}

Pathogenic bacteria utilize several common strategies to overcome host defences and facilitate infections. T3SSs, which deliver effector proteins into host cells, are important virulence mechanisms in Gramnegative bacteria as they interfere with specific cellular and host immune responses to promote bacterial survival and enhance pathogenicity $[1,2]$. Two different T3SSs have been identified in E. coli. The LEEencoded T3SS (ETT1) is well-characterized in EHEC and EPEC strains [4], whereas ETT2 is present, in whole or part, in the majority of E. coli strains, including many commensal strains [6]. However, until now, no prevalence data for ETT2 in APEC isolates have been published.

The present study shows that over half $(57 \cdot 6 \%)$ of 245 APEC isolates harboured the ETT2 locus. We identified five different ETT2 isoforms in these isolates. Sequence analysis showed that there are gene deletions in most APEC strains (types B, C, D, E ETT2 isoforms), indicating that ETT2 has undergone widespread mutational attrition. Similar mutations were also found in other E. coli pathovars [12, 13]. A serotyping analysis indicated that ETT2 was present in the predominant APEC serotypes O78, O2 and O1 with over half $(52 \cdot 5 \%)$ of the isolates being $\mathrm{O} 78$. Further, all the ETT2 elements in isolates of this serotype were variants (not intact), which is consistent with previous studies [10]. Indeed, an intact ETT2 locus was mostly present in serotypes $\mathrm{O} 1$ and $\mathrm{O} 2$ isolates, which also harboured the eip cluster. Further analysis indicated that an intact ETT2 gene cluster was predominant in phylogenetic groups D and B2, as reported previously [6], but by contrast, the distribution of ETT2 mutational isoforms varied.

Our results show that the APEC isolates studied harboured all of the ETT2 isoforms found in human ExPEC (UPEC and NMEC) with a similar frequency as reported for human diarrhoeagenic E. coli $(65 \%)$, Shiga toxin-producing E. coli (STEC) $(100 \%)$, as well as isolates from piglets $(85.9 \%)$ and cows $(47 \cdot 4 \%)$, but was markedly higher than that in UPEC $(3 \%)$ [7, 12-14]. Published studies suggest that ExPEC (APEC, NMEC, UPEC) strains possess a similar broad range of virulence factors and pathogenic mechanisms $[16,17]$. More importantly, the predominant APEC serotypes O1, O2 and O78 have also been implicated in various human diseases, including newborn meningitis and urinary tract infections, indicating that poultry may be a vehicle or even a reservoir for human ExPEC (UPEC and NMEC) $[16-18,24]$. Bacteria could acquire a combination of mobile genetic elements, such as the ETT2 locus, through some mechanism of horizontal gene transfer, and become a highly adapted pathogen [25]. The 1.3-kb IS transposase was found in type $\mathrm{C}$ isoform ETT2 strains, which might facilitate the transfer of ETT2 among E. coli strains.

ETT2 is reported to be associated primarily with the LEE, the high pathogenicity island, the locus of proteolytic activity or Stx2e in intestinal pathogenic E. coli (EHEC and STEC) strains [7, 13, 26]. We investigated the association of ETT2 with the distribution of 15 other APEC virulence factors, but failed to find any correlation between them, which possibly indicates that the ETT2 cluster occurs independently of other virulence factors in these strains, perhaps due to different pathogenicity mechanisms and virulence factors.

Characterized T3SS needle complexes are composed of inner and outer membrane rings and a hollow needle. In most E. coli strains, ETT2 is highly variable and contains mutations, which leads to an incomplete and non-functional T3SS apparatus [6, 12, 13]. Although degenerate, ETT2 still plays a crucial role in E. coli virulence. In EHEC O157:H7, 
ETT2 regulates virulence gene expression and protein secretion by the LEE [8]. The EilA regulator of EAEC 042 coordinately activates the expression of effectors and influences bacterial adherence and biofilm formation, which are indirectly involved in virulence [9]. A degenerate ETT2 in APEC contributes to serum survival and virulence. However, it is not involved in the secretion of effectors. The inactivation of ETT2 affects bacterial surface properties, such as pellicle formation, which might decrease bacterial survival during an infection [10].

Intact ETT2 has been shown to be crucial to bacterial virulence and plays a role in invasion, intracellular survival in HBMECs, and virulence of NMEC [11]. Moreover, in the latter study, the ETT2 deletion mutant exhibited the same levels of OmpA and K1 capsules as wild type, which affect the interaction of $E$. coli K1 with HBMECs, indicating that the ETT2 locus associated with NMEC CE10 has novel properties and mechanisms. It has been shown that the ETT2 T3SS not only secretes proteins that are encoded in the T3SS locus, but also those that are encoded outside of the locus [25]. A previous study [6] and our results show that the eip locus, which encodes homologues of SPI-1 translocators and T3SS-related proteins, was present in all APEC strains harbouring an intact ETT2 cluster. The eip locus might cooperate with ETT2 to construct an active T3SS apparatus. Indeed, E. coli $\mathrm{DH} 5 \alpha$ acquired the ability to secrete the EspB protein when complemented with ETT2 [27]. Additionally, putative T3SS effectors were discovered in EAEC 042, NMEC CE10 and APEC strains $[11,23]$. An intact ETT2 may deliver an unidentified effector(s) into host cells to interfere with host defence and facilitate bacterial infection. The exact function of ETT2 remains unknown, and whether and how an intact ETT2 locus encodes a functional secretion system should be investigated in the future to help us prevent poultry colibacillosis and potential human infections [28].

\section{SUPPLEMENTARY MATERIAL}

For supplementary material accompanying this paper visit http://dx.doi.org/10.1017/S0950268816000820.

\section{ACKNOWLEDGEMENTS}

This work was supported by the National Natural Science Foundation of China (grant nos. 31572523, 31370045 and 31572546), the Chinese Special Fund for Agro-scientific Research in the Public Interest (grant no. 201303044) and the Shanghai Key Project on Agricultural Development through Science and Technology (grant no. 2015HNG1-9).

\section{DECLARATION OF INTEREST}

None.

\section{REFERENCES}

1. Galan JE, et al. Bacterial type III secretion systems: specialized nanomachines for protein delivery into target cells. Annual Review of Microbiology 2014; 68: 415-438.

2. Raymond B, et al. Subversion of trafficking, apoptosis, and innate immunity by type III secretion system effectors. Trends in Microbiology 2013; 21: 430-441.

3. Moest TP, Meresse S. Salmonella T3SSs: successful mission of the secret(ion) agents. Current Opinion in Microbiology 2013; 16: 38-44.

4. Franzin FM, Sircili MP. Locus of enterocyte effacement: a pathogenicity island involved in the virulence of enteropathogenic and enterohemorragic Escherichia coli subjected to a complex network of gene regulation. Biomed Research International 2015; 2015: 534738.

5. Hayashi T, et al. Complete genome sequence of enterohemorrhagic Escherichia coli O157:H7 and genomic comparison with a laboratory strain K-12. DNA Research 2001; 8: 11-22.

6. Ren CP, et al. The ETT2 gene cluster, encoding a second type III secretion system from Escherichia coli, is present in the majority of strains but has undergone widespread mutational attrition. Journal of Bacteriology 2004; 186: 3547-3560.

7. Zhou M, et al. Escherichia coli type III secretion system 2: a new kind of T3SS? Veterinary Research 2014; 45: 32 .

8. Zhang L, et al. Regulators encoded in the Escherichia coli type III secretion system 2 gene cluster influence expression of genes within the locus for enterocyte effacement in enterohemorrhagic E. coli $\mathrm{O} 157: \mathrm{H} 7$. Infection and Immunity 2004; 72: 7282-7293.

9. Sheikh J, et al. EilA, a HilA-like regulator in enteroaggregative Escherichia coli. Molecular Microbiology 2006; 61: 338-350.

10. Ideses D, et al. A degenerate type III secretion system from septicemic Escherichia coli contributes to pathogenesis. Journal of Bacteriology 2005; 187: 8164-8171.

11. Yao Y, et al. The type III secretion system is involved in the invasion and intracellular survival of Escherichia coli $\mathrm{K} 1$ in human brain microvascular endothelial cells. FEMS Microbiology Letters 2009; 300: 18-24.

12. Cheng D, et al. Prevalence and isoforms of the pathogenicity island ETT2 among Escherichia coli isolates from colibacillosis in pigs and mastitis in cows. Current Microbiology 2012; 64: 43-49.

13. Prager R, et al. Prevalence and deletion types of the pathogenicity island ETT2 among Escherichia coli 
strains from oedema disease and colibacillosis in pigs. Veterinary Microbiology 2004; 99: 287-294.

14. Osawa K, et al. Identification of the ETT2 locus in human diarrheagenic Escherichia coli by multiplex PCR. Journal of Infection and Chemotherapy 2006; 12: 157-159.

15. Miyazaki J, et al. Identification of a type III secretion system in uropathogenic Escherichia coli. FEMS Microbiology Letters 2002; 212: 221-228.

16. Tivendale KA, et al. Avian-pathogenic Escherichia coli strains are similar to neonatal meningitis E. coli strains and are able to cause meningitis in the rat model of human disease. Infection and Immunity 2010; 78: 3412-3419.

17. Ewers C, et al. Avian pathogenic, uropathogenic, and newborn meningitis-causing Escherichia coli: how closely related are they? International Journal of Medical Microbiology 2007; 297: 163-176.

18. Johnson TJ, et al. Comparison of extraintestinal pathogenic Escherichia coli strains from human and avian sources reveals a mixed subset representing potential zoonotic pathogens. Applied and Environmental Microbiology 2008; 74: 7043-7050.

19. Wang S, et al. DotU expression is highly induced during in vivo infection and responsible for virulence and Hcp1 secretion in avian pathogenic Escherichia coli. Frontiers in Microbiology 2014; 5: 588.

20. Wang S, et al. Development of an allele-specific PCR assay for simultaneous sero-typing of avian pathogenic Escherichia coli predominant O1, O2, O18 and $\mathrm{O} 78$ strains. PLoS ONE 2014; 9: e96904.
21. Clermont O, Bonacorsi S, Bingen E. Rapid and simple determination of the Escherichia coli phylogenetic group. Applied and Environmental Microbiology 2000; 66: 4555-4558.

22. Meng Q, et al. Development and application of multiplex PCR assay for detection of virulence genes in Avian pathogenic E. coli. Acta Microbiologica Sinica 2014; 54: 696-702.

23. Chaudhuri RR, et al. Complete genome sequence and comparative metabolic profiling of the prototypical enteroaggregative Escherichia coli strain 042. PLoS ONE 2010; 5: e8801.

24. Rodriguez-Siek KE, et al. Comparison of Escherichia coli isolates implicated in human urinary tract infection and avian colibacillosis. Microbiology 2005; 151: 2097 2110.

25. Brown NF, Finlay BB. Potential origins and horizontal transfer of type III secretion systems and effectors. Mobile Genetic Elements 2011; 1: 118-121.

26. Schmidt $\mathbf{H}$, et al. Identification and characterization of a novel genomic island integrated at selC in locus of enterocyte effacement-negative, Shiga toxin-producing Escherichia coli. Infection and Immunity 2001; 69: 6863-6873.

27. Makino S, et al. Distribution of the secondary type III secretion system locus found in enterohemorrhagic Escherichia coli O157:H7 isolates among Shiga toxinproducing E. coli strains. Journal of Clinical Microbiology 2003; 41: 2341-2347.

28. Lee VT, Kessler JL. Type III secretion systems as targets for novel therapeutics. IDrugs 2009; 12: 636-641. 